\title{
Estimation of Global Solar Radiation for Ikeja, Enugu and Kano, Nigeria
}

\author{
1*AKINPELU, JA; ${ }^{2}$ OLAWALE, OK; ${ }^{1}$ OMOLE, OT \\ *l Department of Physics and Solar Energy, Bowen University, Iwo, Nigeria \\ ${ }^{2}$ Department of Science Laboratory Technology, Federal Polytechnics, Ede, Nigeria \\ *Corresponding Author Email: jacob.akinpelu@bowenuniversity.edu.ng
}

\begin{abstract}
Estimations of global solar radiation based on a model of using normalized clearness index and normalized sunshine duration for a period of up to 25 years $(1985-2010)$ for Ikeja $\left(06.39^{\circ} \mathrm{N}, 03.20^{\circ} \mathrm{E}\right)$, Enugu $\left(06.28^{0} \mathrm{~N}\right.$, $07.35^{\circ} \mathrm{E}$ ), and Kano (12.03 N, 08.32E), Nigeria for each climatological stations were established. The monthly average total solar radiation was also estimated. The reliability index of the calculation varies from 2.4 to 2.6 percent. The overall results show that for Kano, the received radiation on the plane surface is higher than for Ikeja and Enugu.
\end{abstract}

\section{DOI: https://dx.doi.org/10.4314/jasem.v22i12.1}

Copyright: Copyright $\odot 2018$ Akinpelu et al. This is an open access article distributed under the Creative Commons Attribution License (CCL), which permits unrestricted use, distribution, and reproduction in any medium, provided the original work is properly cited.

Keywords: Global solar radiation, Clearness index, Sunshine duration, Reliability index

Solar radiation is the energy that comes from the sun which generate huge amount of energy through the process of nuclear fusion. Solar radiation is the ultimate control of weather and climate because it is the only source of the earth's energy. Energy sources are vital and essential ingredients for all human transactions and without them human activities of all kinds will not be progressive at all. Knowledge of the solar radiation is essential for many applications, including architectural design, solar energy systems, crop growth models and evapotranspiration estimable. The global solar radiation on horizontal surface at the location of interest is the most critical input parameter employed in the design and prediction of the performance of solar energy device. (Hussain, et al, 1999). Global solar radiation is an important parameter necessary for most ecological models and serves as input for different photovoltaic conversion system; hence, it is of economic importance to renewable energy alternative. The solar radiation reaching the earth's surface depends on the climatic condition of the specific site location, and this is essential for accurate prediction and design of a solar energy system (Burari and Sambo, 2001).

\section{MATERIALS AND METHODS}

The monthly parameters of solar radiation, sunshine duration, maximum temperature and minimum temperature from 1985-2005 were obtained at Nigeria Meteorological station Oshodi for Ikeja, Enugu and Kano synoptic stations, Nigeria. The duration of solar radiation, which is the most important data for meteorological models, has been studied in the present work for Ikeja, Enugu, and Kano; the geographical positions for which are given in Table 1 below.

Table 1: Geographical location of the stations.

\begin{tabular}{lll}
\hline Station & Latitude & Longitude \\
\hline Ikeja & $06.39^{\circ} \mathrm{N}$ & $03.20^{\circ} \mathrm{E}$ \\
Enugu & $06.28^{\circ} \mathrm{N}$ & $7.35^{\circ} \mathrm{E}$ \\
Kano & $12.03^{\circ} \mathrm{N}$ & $8.32^{\circ} \mathrm{E}$ \\
\hline
\end{tabular}

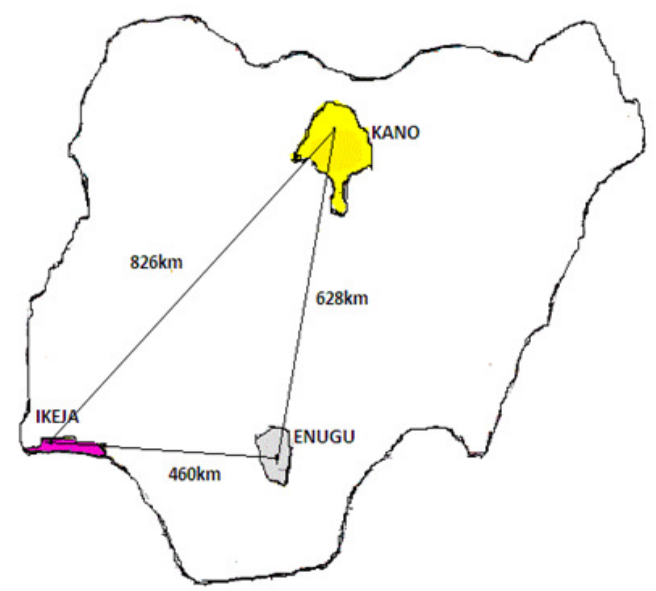

Fig 1: map of Nigeria showing studying stations and the distance between them

Various climatic parameters have been used in developing empirical relations for predicting the monthly average global solar radiation. Among the existing correlations, the following relation is the generally accepted modified form of the Angstromtype regression equation, relating the monthly average daily global radiation to the average daily sunshine hours and is given as: 


$$
\frac{H}{H_{0}}=\left(a+b\left(\frac{S}{S_{0}}\right)\right) \ldots \ldots . .(1)
$$

Regression Equation above has been found to accurately predict global solar radiation in several locations. Here $\mathrm{H}$ is the measured monthly average daily global radiation on a horizontal surface $\left(\mathrm{MJm}^{-2}\right.$ day $\left.^{-1}\right), \mathrm{H}_{0}$ is the monthly average daily extraterrestrial radiation on a horizontal surface $\left(\mathrm{MJm}^{-2}\right.$ day $\left.^{-1}\right), S$ is the monthly average daily number of hours of bright sunshine, $\mathrm{S}_{0}$ is the monthly average daily maximum number of hours of possible sunshine (or day length) and $a ; b$ are regression constants to be determined. (Angstrom AS, 1924). The regression coefficient $a$ and $b$ are empirical constant obtained from the relationship given as

$$
\begin{aligned}
& a=-0.110+0.235 \cos \phi+0.323\left(\frac{S}{S_{0}}\right) \ldots \\
& b=1.449-0.553 \cos \phi-0.694\left(\frac{S}{S_{0}}\right) \ldots \ldots
\end{aligned}
$$

(Tiwari and Sangeeta, 1997)

The accuracy of the estimated values was tested by calculating the Mean Bias Error (MBE), Root Mean Square Error (RMSE), and Mean Percentage Error (MPE). The expressions for the MBE $\left(\mathrm{MJm}^{-2} \mathrm{day}^{-1}\right)$, RMSE $\left(\mathrm{MJm}^{-2} \mathrm{day}^{-1}\right.$ ), and MPE (\%) is stated as Equation 4 - 6

$$
\begin{aligned}
& M B E=\left[\sum\left(H_{i(c a l)}-H_{i(\text { mass })}\right)\right] / n \\
& R M S E=\left\{\left[\sum\left(H_{i(c a l)}-H_{i(\text { meas })}\right)^{2}\right] / n\right\}^{1 / 2} \cdots
\end{aligned}
$$$$
H_{0}=\frac{24 \times 3600 G_{s c}}{\pi}\left[1+0.033 \cos \left(\frac{360 n}{365}\right)\right] \times\left[\cos \phi \cos \delta \sin \omega_{s}+\frac{2 \pi \omega_{s}}{360} \sin \phi \sin \delta\right] \ldots
$$

Where $\mathrm{H}_{\mathrm{e}}$ is the arithmetic mean value of the $m$ estimated values of the global solar radiation and $\mathrm{H}_{\mathrm{m}}$ is the arithmetic mean value of the $M$ measured values of the global solar radiation. $\mathrm{M}$ is the total number of observation points for the measured values of the global solar radiation and $\mathrm{m}$ is the total number of predicted points for the estimated values of the global solar radiation. The extraterrestrial solar radiation on a horizontal surface were calculated from the following equation given by Iqbal (1983) as follows:
The eccentricity correction factor equation developed by Iqba (1983) is given as

$$
\left.M P E=\left[\sum\left\{\left(\left(H_{i(\operatorname{meas})}-H_{i((c a))}\right) / H_{i(\operatorname{mess})}\right) \times 100\right\}\right)\right] / n
$$

Where $\mathrm{H}_{\mathrm{i}}$, cal and $\mathrm{H}_{\mathrm{i} \text {, meas }}$ is the ith calculated (predicted) and measured values and $\mathrm{n}$ is the total number of Almorox (2005) have recommended that a zero value for MBE is ideal and a low RMSE is desirable. The RMSE test provides information on the short- term performance of the studied model as it allows a term by term comparison of the actual deviation between the calculated values and the measured values. The test gives long term performance of the perations regression equations, a positive MPE values calculated values, while the negative values gives underestimation. A low value of MPE is desirable by Akpabio et al., (2002). The correlation coefficients $r$ between estimated and measured radiation values was defined by

$$
r=\frac{\sum\left(\bar{H}_{\text {estimated }}-\bar{H}_{\epsilon}\right)\left(\bar{H}_{\text {measwed }}-\bar{H}_{m}\right)}{\sqrt{\left(\sum\left(\bar{H}_{\text {estimated }}-\bar{H}_{\epsilon}\right)^{2}\right)\left(\sum\left(\bar{H}_{\text {mearwed }}-\bar{H}_{m}\right)^{2}\right)}} \cdots . .(7)
$$

$$
\mathrm{E}_{0}=1+0.033 \cos \left(\frac{360 N}{365}\right) \ldots
$$

Where $\mathrm{N}$ is the Julian day (day number ranging from $\mathrm{N}=1$ on 1 st January to $\mathrm{N}=365$ on 31 st December).

An approximate equation developed for the declination of the sun, which was presented by Igbal (1983) is given as;

$$
\delta=23.45 \sin \left[\frac{360(N+284)}{365}\right] \ldots
$$

The hour angle $\mathrm{W}_{\mathrm{s}}$ for horizontal surface is given as, 


$$
W_{s}=\cos ^{-1}(-\tan \phi \tan \delta) \text {. }
$$

Where $\varphi$ is the latitude and $\delta$ is the solar declination angle.

The day length $S_{0}$ is the number of hours of sunshine or darkness within the 24 hours in a given day. It is also referred to as the maximum possible sunshine duration. For a horizontal surface it is given by

$$
S_{0}=\frac{2}{15} \cos ^{-1}(-\tan \phi \tan \delta)=\frac{2}{15} W_{s}
$$

\section{RESULTS AND DISCUSSIONS}

From Figure 2, 3, 4 the maximum values of global solar radiation appears in April, May and April with 13.89 $\mathrm{MJm}^{-2}$ day $^{-1}, 14.70 \mathrm{MJm}^{-2} \mathrm{day}^{-1}$ and $19.24 \mathrm{MJm}^{-}$ ${ }^{2}$ day $^{-1}$ for Ikeja, Enugu and Kano respectively during dry season while minimum values of $8.92 \mathrm{MJm}^{-2}$ day 1, $9.81 \mathrm{MJm}^{-2}$ day $^{-1}$ and $15.90 \mathrm{MJm}^{-2}$ day $^{-1}$ were observed in July, August and December for Ikeja, Enugu and Kano respectively during wet season. It is observed also that the sunshine duration is up to 65 percent throughout the year for the three locations. The analysis of the measured and calculated $H$ shows that for all locations, the maximum values of global solar radiation are observed in April while the minimum values appeared around August. The observed value changes for these sites depend largely on their geographical locations. Furthermore, in order to relate the observed values of clearness index with sunshine duration, the parameters employing the regression constant "a" and " $b$ " are evaluated and inserting the values in Equation (1) to estimate the monthly average daily global solar radiation $\mathrm{H}$. These values are fitted in an empirical equation as follows:

$$
\begin{aligned}
& H=H_{0}\left[0.42+0.28\left(\mathrm{~s} / \mathrm{S}_{0}\right)\right] \text { IKEJA } \\
& H=H_{0}\left[0.47+0.28\left(\mathrm{~s} / \mathrm{S}_{0}\right)\right] \text { ENUGU } \\
& H=H_{0}\left[0.63+0.32\left(\mathrm{~s} / \mathrm{S}_{0}\right)\right] \text { KANO }
\end{aligned}
$$

For testing of the performance, a statistical analysis of the results was performed for the RMSE, MBE, and MPE which represent the fundamental measured accuracy of the data. While MPE is the reliability index as given in Table 2, the MPE ranging from 2.4 to 2.6 is a very good reliable index to the present calculation. Also, correlation coefficients (0.5 - 0.9) are high for all of the variables of the locations. This implies that, there are statistically significant relationships between the clearness index and relative sunshine duration.

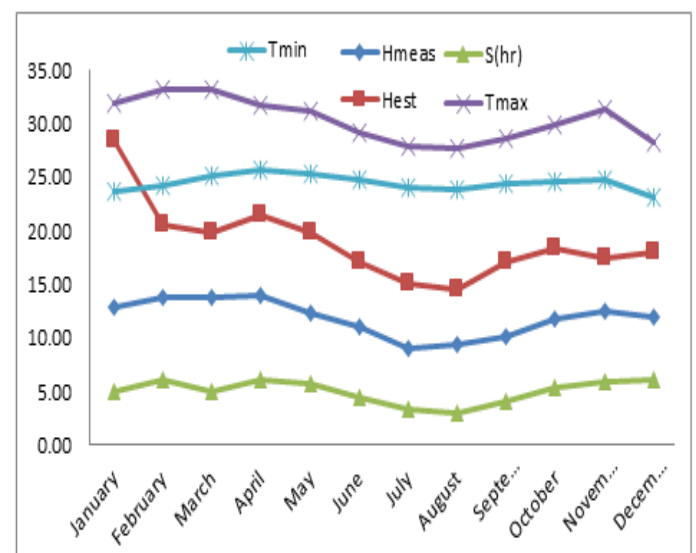

Fig 2: Monthly variation of $\mathrm{H}_{\text {meas }}\left(\mathrm{MJm}^{-2} \mathrm{day}^{-1}\right), \mathrm{H}_{\mathrm{est}}\left(\mathrm{MJm}^{-2} \mathrm{day}^{-1}\right)$, $\mathrm{S}(\mathrm{hr}), \mathrm{T}_{\max }\left({ }^{\circ} \mathrm{C}\right)$ and $\mathrm{T}_{\min }\left({ }^{\circ} \mathrm{C}\right)$ for Ikeja $(1985-2010)$.

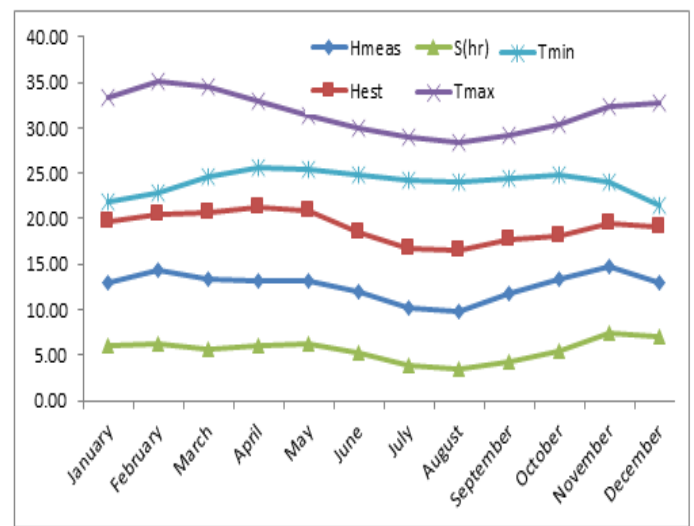

Fig. 3: Monthly variation of $\mathrm{H}_{\text {meas }}\left(\mathrm{MJm}^{-2}\right.$ day $\left.^{-1}\right), \mathrm{H}_{\mathrm{est}}\left(\mathrm{MJm}^{-2} \mathrm{day}^{-1}\right)$, $\mathrm{S}(\mathrm{hr}), \mathrm{T}_{\max }\left({ }^{0} \mathrm{C}\right)$ and $\mathrm{T}_{\min }\left({ }^{0} \mathrm{C}\right)$ for Enugu (1985-2010).

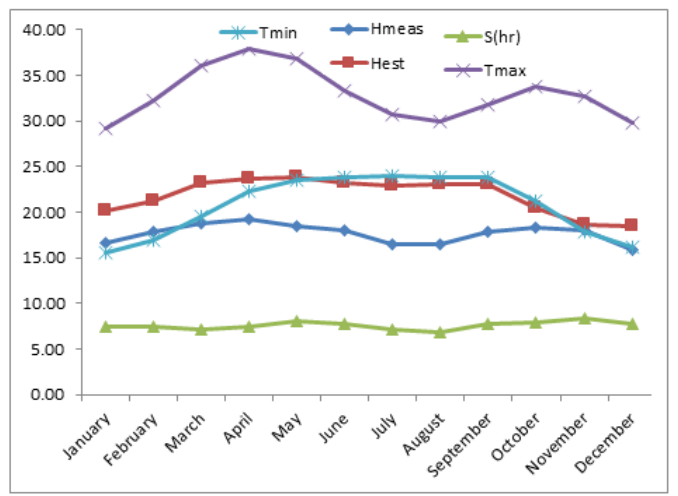

Fig 4: Monthly variation of $\mathrm{H}_{\text {meas }}\left(\mathrm{MJm}^{-2}\right.$ day $\left.{ }^{-1}\right), \mathrm{H}_{\text {est }}\left(\mathrm{MJm}^{-2}\right.$ day $\left.^{-1}\right)$, $\mathrm{S}(\mathrm{hr}), \mathrm{T}_{\max }\left({ }^{\circ} \mathrm{C}\right)$ and $\mathrm{T}_{\min }\left({ }^{\circ} \mathrm{C}\right)$ for Kano $(1985-2010)$.

Table 2: Regression coefficient and reliability index

\begin{tabular}{lllllll}
\hline Site & $\mathrm{a}$ & $\mathrm{b}$ & MBE & RMSE & MPE & $\mathrm{r}$ \\
\hline Ikeja & 0.28 & 0.61 & 0.0071 & 3.356 & 2.443 & 0.500 \\
Enugu & 0.47 & 0.28 & 0.308 & 3.692 & 2.200 & 0.857 \\
Kano & 0.63 & 0.32 & -0.294 & 3.126 & 2.645 & 0.957 \\
\hline
\end{tabular}

Conclusion: The performance of the model developed was investigated. It was found that global radiation calculated from the model is in good agreement with 
that obtained from measurement. The monthly average daily clearness index $H / H_{o}$ and the relative possible sunshine duration $\quad S / S_{o}$ for the selected locations have been proposed. It is concluded that the correlation proposed for these site can be used successfully for estimation of $H$ for any location of Nigeria with similar meteorological characteristics.

\section{REFERENCES}

Akpabio, LE; Etuk, SE (2002). Relationship between solar radiation and sunshine duration for Onne Nigeria. Turk. J. Phy. 27: 161-167.

Almorox, J; Benito, M; Hontoria, C., (2005). Estimating of Monthly Angstrom Prescott quotation coefficients from measured daily data in Toledo, Spain. Renewable Energy J. 30: 93 99.

Burari, F.W; Sambo, AS., (2001); Model for the prediction of global solar for Bauchi using Meteorological Data, Niger. J. Renewable Energy 91: 3033.

Fayadh, M; Abed, Al-Dulaimy; Ghazi-Yousif Mohammed, Al-Shahany, (2010). Estimation of global solar radiation on horizontal surfaces over Hadith, Samara and Beji, Iraq. Pacific J Sci. Technol., 11 (1) 73-82.

Gana, NN; Akpootu, DO. (2013b). Estimation of global solar radiation using four sunshine based models in Kebbi, North-Western, Nigeria. $A d v$. Sci. Res. 4(5), 409-421.
Gana, NN;Rai, JK ;Momoh, M (2014). Angstrom Constants for Estimating Solar Radiation in Sokoto, North-Western, Nigeria. Inter. J. Sci. Engineer. Res. 5(1), 1636-1647.

Halouani, N, and .Ngguyen, C (1993) Calculation of monthly average global solar radiation on horizontal surface using daily hours of bright. Solar Energy, 50:247-258

Hussain, M , Rahman L and Rahman MM (1999): Journal of Renewable Energy 18. 263-275

Iqbal, M. (1983). An Introduction to Solar Radiation, Department of Mechanical Engineering University of British Coloubia, Califonia

Massaquoi, JGM (1988). Global solar radiation in Sierra Leone (West Africa). J. Solar Wind Technol. 5. 281-283.

Rietveld, MR (1978). A new method for estimating the regression coefficients in the formula relating solar radiation to sunshine. J. Agric. Meteorol. 19. 243-252.

Sambo, AS (1986). Empirical models for the correlation of global solar radiation with meteorological data for northern Nigeria. $J$. Solar Wind Technol. 3 (2) 89.

Tiwari RF and Sangeeta TH (1997): Soar Energy. 24 (6) $89-95$ 